\title{
Johne's Disease in Domestic Animals and its Zoonotic Significance: A Review Article
}

\author{
Yash Bhargava ${ }^{1}$, Sushant Sharma ${ }^{2}$, Amit Singh Vishen ${ }^{3 *}$, \\ Jagnoor Singh Sandhu ${ }^{4}$ and Abhishek Mishra ${ }^{5}$
}

${ }^{I}$ Division of Parasitology, Sher-E-Kashmir University of Agricultural Sciences \& Technology of Jaтmu, Jaтmu \& Kashmir, India

${ }^{2}$ Veterinary officer polyclinic, Dholpur, Rajasthan, India

${ }^{3}$ Department of Veterinary Anatomy, C. V. Sc. \& A. H., Acharya Narendra Dev University of Agriculture \& Technology, Ayodhya, U.P., India

${ }^{4}$ Faculty of Veterinary Sciences \& Animal Husbandry, Sher-E-Kashmir University of Agricultural Sciences \& Technology of Jaтmu, Jammu \& Kashmir, India ${ }^{5}$ College of Veterinary Sciences \& Animal Husbandry, DUVASU, Mathura, India

*Corresponding author

\section{A B S T R A C T}

Johne's disease is a fatal gastrointestinal disease of ruminants and is caused by the Mycobacterium avium paratuberculosis (MAP). It is a zoonotic disease and in

\section{Keywords}

Johne's, Crohn's disease, Zoonosis and ruminants

Article Info

\section{Accepted:}

10 July 2020

Available Online:

10 August 2020 humans transmits as Crohn's disease. The main clinical symptoms of Johne's disease in ruminants are Severe diarrhoea with the increased thirst, progressive cachexia, emaciation, body coat is rough and hide bound condition. Humans can be exposed to the MAP through the consumption of raw milk of the infected dairy-herd with the pathogen, ground beef from the infected buffalo, domestic water supply which is originating from the surface source near the runoff from infected farms and improper pasteurization of milk. The large intestinal mucosa becomes cobble stone appearance in Crohn's disease though it is corrugated in the JD. The treatment of this disease is not advocated but the vaccination could be done with heat killed or modified live preparation of Mycobacterium avium paratuberculosis strain-18. There should be maintenance of personal hygiene and use of boots, hand gloves and caps during handling of the animals.

\section{Introduction}

There are many infectious diseases which show early symptoms in domestic animals after getting infection, though in another side there are certain diseases whose causative agent takes time to reflect a clinical sign in patient after enters the body and starts to 
damage at cellular and tissue level in the body. Johne's disease in ruminants and Crohn's disease in humans are two of them, which are supposed to be caused by same pathogen and having a good zoonotic potential. It slowly starts to damage the body internally and cause the emaciation of the animals by causing hypoproteinemia. The farmers of developed and developing countries will get heavy production losses from the disease which is generally undiagnosed in the herds.

\section{Causative agent and its characteristics}

It is a bacterial disease caused by the Mycobacterium avium paratuberculosis (MAP). They are non-motile, non-spore forming, aerobic or microaerophilic bacteria. Ziehl-neelson stain (Mangalakumari Jeyanathan et al., 2006), kynioun stain and fluorescent stain (Patrick and Houston, 1998) can be used for staining and diagnosis purpose. They are known as acid fast organisms based on their cell wall which consist of mycolic acids (hydroxy acid containing caboxyl groups) and overlayed with a variety of polypeptides and glycolipids. Both type of innate and adaptive immune response are activated by this type of cell wall.

The classification of bacteria-

Kingdom- Monera

Phylum- Actinobacteria, Order- Actinomycetales, Suborder- Corynebacterineae, Family- Mycobactericeae, Genus- Mycobacterin, Species- Avium, Subspecies- Paratuberculosis.

They are slow growing bacteria and their generation time is 14-15 hours and the optimum $\mathrm{pH}$ ranges from 6.4 to 7 and it is eugenic bacteria (the addition of 5\% glycerol causes luxuriant growth) and $5 \%$ of $\mathrm{CO}_{2}$ in the atmosphere aids growth. LowensteinJenson medium, Dorset-egg medium, Loeffler's medium, Pawlowsky's medium, Tarshi 's medium, Middlebrookbiplate agar media are some of the solid media and Dubos media, Middlebrooks Proskauer and Beck's media, Sula and Sauton's media are some of the liquid media used for culture of bacteria. Biochemical activities evaluated were growth at $30{ }^{\circ} \mathrm{C}, 37{ }^{\circ} \mathrm{C}$, and $42{ }^{\circ} \mathrm{C}$; production of urease, niacin, pyrazinamidase, arylsulfatase, and catalase; hydrolyzation of Tween 80; reduction of nitrate and tellurite; and growth in $5 \% \mathrm{NaCl}$. They shed by the infected animals in the feaces and are wide spread in soil, pastures, grass and water.

Susceptible species- it is a fatal gastrointestinal disease of ruminants such as cattle, buffalo, sheep and goat (Marquetoux et al., 2018) but generally cattle of age 3-5 years are more prone to the infection.

\section{Pathogenesis of disease}

The disease occurs in three groups- Infected which do not shed organism in the faeces and have no clinical disease; infected which shed organism in the faeces but have no clinical disease; and infected which shed the organism in the faeces and have clinical disease.

Bacteria enters the body of animal through feco-oral route (Irengea et al., 2008) via contaminated feed, pasture, water and generally in acidic soil reaches the intestine. There it settles in the lamina propria of intestines or in inside the intestinal mucosa. The bacteria multiply there and cause bacteraemia. The bacteria reaches the local lymphnodes (Christophe Coetsier et al., 1998) and cause chronic granulomatous inflammation. It also promotes type-III hypersensitivity which may contribute to the 
development of intestinal lesions causing diarrhoea and the hypoproteinemic condition in the animal.

The bacteria multiplies in the lining of the intestine and the associated lymphoid tissue, but it can also be multiply within the macrophages which carry the organisms to other tissues in the animal body and it can also spread throughout the body but this condition is rare. Initially cell mediated immune response is there and later on antibodies appear likely in response to the presence of Mycobacterium avium paratuberculosis by dying macrophages. The immune response of the animal is responsible for the diarrhoea in the affected animal. The bacteria is present in the intestine and the inflammatory cells respond to the bacteria in the intestine results in the damage of the intestinal wall or lining of the animal and it is interesting to know that the severity of the disease is reduced or clinical form of the disease disappear in the pregnant cows as the immune system is suppressed during the pregnancy.

\section{Clinical signs and its zoonotic importance}

Severe diarrhoea with the increased thirst but the appetite is normal progressive cachexia. Animal is emaciated, body coat is rough and hide bound condition appears. The cardinal symptom of the disease is intermittent or continuous leading to progressive emaciation and death (Garvey, 2018).

It is a zoonotic disease and in humans transmits as Crohn's disease (Rosenfeld and Bressler, 2010). Mycobacterium paratuberculosis is a bacterium which causes zoonotic disease and can be transmitted from bovines to the humans and cause crohn's disease. There is general malaise, abdominal pain, diarrhoea, and chronic weight loss as it is a chronic inflammatory condition of gastrointestinal tract and can affect any part of it. Its cure and treatment is poor and do not give proper result, thus it is a lifelong disease but not life threatening disease. It generally affects to 16-25 years age of adults, but sometimes also occurs in old age and child hood stages. Symptomatic treatment is adopted for treatment, surgery could also be done to remove the affected area/bowel. It can occur at 24 different sites and on the basis of these sites the disease is categorized in 24 sub-groups.

Humans can be exposed to the MAP through the consumption of raw milk of the infected dairy-herd with the pathogen, ground beef from the infected buffalo, domestic water supply which is originating from the surface source near the runoff from infected farms, improper pasteurization of milk -HTST. In 1984, Micobacterium paratuberculosis is first reported from the crohn's disease patient from which it is isolated. It is a common disease of developed rather than undeveloped and developing countries.

There are certain differences between the crohn's disease and Johnes disease- in clinical stage there is obstruction in Crohn's disease while there is no obstruction in the JD in the intestine, skin lesions are seen in Crohn's disease but not seen in JD. The pathological difference includes the lesions in the oral cavity and oesophagus in Crohn's disease. The macroscopic appearance of bowel wall in Crohn's disease is edematous and garden hose like appearance while in JD it is thickened. There is stenosis and perforation is there in Crohn's disease which is rare in cases of JD. There is fistula and pseudopolyps in Crohn's disease. The mucosa becomes cobble stone appearance in Crohn's disease, though it is corrugated in the JD in large intestine. Fibrosis and fissures can be seen under microscope in the histopathological section of crohn's disease and acid fast bacilli can be 
seen in the sample for the microscopic lab diagnosis for JD.

\section{Post-Mortem Lesions}

Macroscopic lesion: There is thickening of the terminal part of the ileum and oedematous. Segmental thickening of the ileum, caecum, and proximal colon and the affected segments have a variably thickened, rough, rugose mucosa, often with multiple foci of ulceration. There is corrugation in large intestine. There is lymphadenopathy in the mesentry. In some cases the vascular lesion also found as there is mineralization of aorta and endocardium that is called arteriosclerosis.

Microscopic lesion: There is infiltration of epithelioid cells in mucosa, submucosa and in mesenteric lymphnodes. The thickening of sub mucosa, oedema and infiltration with inflammatory cells can be observed under the microscope the bacterium is observed in ileocaecal valve smear. There are numerous foamy macrophages with acid fast organisms contained in the non-caseting granulomas (Matos et al., 2017).

\section{Diagnosis of disease}

There are several techniques which aid in diagnosis-

Rectal smear method,

Laparotomy,

Growth characteristics,

Morphological characteristic,

Genetic identification (by PCR),

ELISA

Complement Fixation Test (Gold Standard Test)

Gamma-interferon test

Graph.1 Growth curve of Mycobacterium avium subspecies paratuberculosis ('S 5') strain upto 8 weeks by taking OD at 600nm (Auster et al., 2019)

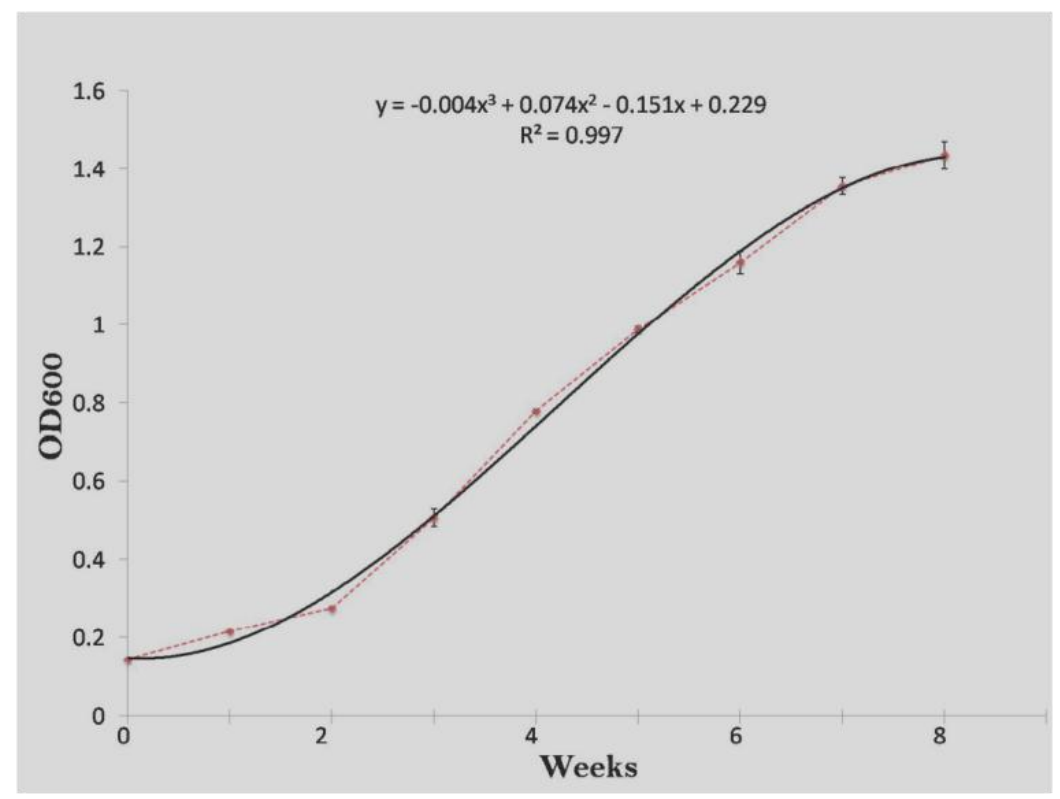

In rectal smear a small piece of the rectum is pinched out, washed and squeezed between two slides, the resulting smear and other smears are stained with Ziehl-Neelsen method 
(Allen, 1992). Johne's bacilli occurs singly and in characteristic clumps and stain a pinkish red. In laparotomy a reliable but complicated procedure to examine smear in biopsies of mesenteric lymph nodes taken in the region of the terminal for acid fast organisms (Hotaling et al., 2001). The gamma interferon test is based on the animal's cellular immune response to the Mycobacterium avium paratuberculosis and this test is able to detect infected animals before the antibodies start to develop and the organisms start to shed in the feaces but one major disadvantage with this test that the chilled blood sample should be delivered to the laboratory diagnosis within hours of collection which is rarely possible in field condition. The organism grows very slow and cultivation and identification may take months the feces or tissue is treated as contaminants.

\section{Dispatch of the clinical sample}

Rectal pinch swab or smear, fecal sample, terminal portion of ileum with ileocaecal valve, mesenteric lymph gland in $10 \%$ formal saline will be sample of choice for dispatch. In case of delay if material is collected for bacteriological examination then it should be kept at refrigeration temperature.

\section{Treatment of disease}

The combination of streptomycin, rifampicin and levamisole is used but they are not cost effective and the infection again develops after discontinuation of the drugs, thus test and slaughter policy is adopted for it. Therefore treatment of this disease is not advocated (Savarino et al., 2019).

\section{Vaccination and control}

Vaccination could be done; heat killed or modified live preparation of Mycobacterium avium paratuberculosis strain-18 can be used for sheep and goat (Park and Yoo, 2016). Calf from the dam is completely separated from the lactating and dry herd. The lactating and dry herd should be completely separated from the maternity area. All the milking equipment should be properly cleaned and disinfected daily as because the bacteria also shed in the milk. Sheds should be cleaned frequently and well drained. Raise the $\mathrm{pH}$ of environment/soil with lime. Drainage from the sheds should not be towards the pasture land. Sometimes the bacteria sheds in the semen so bulls should tested before semen collection. There should be maintenance of personal hygiene and use of boots, hand gloves, caps during handling of the animals. Milk should be consumed after pasteurization by HTST method (Eslami et al., 2018).

\section{References}

Allen, J.L. 1992. A modified Ziehl-Neelsen stain for mycobacteria. Medical laboratory sciences, 49(2): 99-102.

Auster, L., Sutton, M., Gwin, M.C., Nitkin, C. and Bonfield, T.L. 2019. Optimization of In Vitro Mycobacterium avium and Mycobacterium intracellulare Growth Assays for Therapeutic Development. Microorganisms, 7(2): 42.

Christophe C., Xavier H., Francois M., Sanaa S., Francoise C., Klaus B., Bernard L., Dominique L., Herve B., Jean F.D. and Carlo C. 1998. Clinical and Diagnostic Laboratory Immunology, Jul 5 (4): 446451.

Savarino E. , Bertani L., Ceccarelli L., Bodini G., Zingone F., Buda A., Facchin S., Lorenzon G., Marchi S., Marabotto E., Bortoli D.N., Savarino V. , Costa F. and Blandizzi C. 2019. Antimicrobial treatment with the fixed dose antibiotic combination RHB-104 for Mycobacterium avium subspecies paratuberculosis in Crohn's disease: 
pharmacological and clinical implications, Expert opinion on biological therapy.

Eslami, M., Shafiei, M., Ghasemian, A. 2018. Mycobacterium avium paratuberculosis and Mycobacterium avium complex and related subspecies as causative agents of zoonotic and occupational diseases. $J$ Cell Physiol., 234: 12415-12421

Mangalakumari J., David C. Alexander, Christine Y. T., Christiane G., Marcel A. 2006. Evaluation of In Situ methods used to Detect Mycobacterium avium subsp. paratuberculosis in Samples from Patients with Crohn's Disease Behr Journal of Clinical Microbiology, 44 (8) 2942-2950.

Garvey, M. 2018. Mycobacterium avium subspecies paratuberculosis: A possible causative agent in human morbidity and risk to public health safety. Open veterinary journal, 8(2): 172-181.

Léonid M. Irenge, Karl Walravens, Marc Govaerts, Jacques Godfroid, Valérie Rosseels, et al., Development, validation of a triplex real-time PCR for rapid detection and specific identification of $M$. avium subsp. paratuberculosis in faecal samples. Veterinary Microbiology, Elsevier, 2009, $136 \quad$ (1-2), pp.166. ff10.1016/j.vetmic.2008.09.087ff. ffhal00532519f

Marquetoux, N., Mitchell, R., Ridler, A. et $a l$., A synthesis of the patho-physiology of Mycobacterium avium subspecies paratuberculosis infection in sheep to inform mathematical modelling of ovine paratuberculosis. Vet Res 49, 27 (2018).

Matos, A. C., Figueira, L., Martins, M. H., Matos, M., Álvares, S., Mendes, A., Pinto, M. L., and Coelho, A. C. (2017). Detection of Mycobacterium avium subsp. paratuberculosis in kidney samples of red deer (Cervus elaphus) in Portugal: Evaluation of different methods. The Journal of veterinary medical science, 79(3), 692-698.

Park, H. T., and Yoo, H. S. (2016). Development of vaccines to Mycobacterium avium subsp. paratuberculosis infection. Clinical and experimental vaccine research, 5(2), 108-116.

Ramage, G., S. Patrick, and S. Houston. 1998, Combined fluorescent in situ hybridisation and immunolabelling of Bacteroides fragilis. Journal of immunological methods 212:139-147.

Rosenfeld, G., and Bressler, B. (2010). Mycobacterium avium paratuberculosis and the etiology of Crohn's disease: a review of the controversy from the clinician's perspective. Canadian journal of gastroenterology = Journal canadien de gastroenterologie, 24(10), 619-624.

Somoskövi A, Hotaling JE, Fitzgerald M, et al., Lessons from a proficiency testing event for acid-fast microscopy. Chest. $2001 \mathrm{Jul} ; 120(1): 250-257$.

\section{How to cite this article:}

Yash Bhargava, Sushant Sharma, Amit Singh Vishen, Jagnoor Singh Sandhu and Abhishek Mishra. 2020. Johne's Disease in Domestic Animals and its Zoonotic Significance: A Review Article. Int.J.Curr.Microbiol.App.Sci. 9(08): 231-236. doi: https://doi.org/10.20546/ijcmas.2020.908.026 